\title{
The early argument for prefrontal leucotomy: the collision of frontal lobe theory and psychosurgery at the 1935 International Neurological Congress in London
}

\author{
Lillian B. Boettcher, BA, and Sarah T. Menacho, MD \\ Department of Neurosurgery, Clinical Neurosciences Center, University of Utah, Salt Lake City, Utah
}

The pathophysiology of mental illness and its relationship to the frontal lobe were subjects of immense interest in the latter half of the 19th century. Numerous studies emerged during this time on cortical localization and frontal lobe theory, drawing upon various ideas from neurology and psychiatry. Reflecting the intense interest in this region of the brain, the 1935 International Neurological Congress in London hosted a special session on the frontal lobe. Among other presentations, Yale physiologists John Fulton and Carlyle Jacobsen presented a study on frontal lobectomy in primates, and neurologist Richard Brickner presented a case of frontal ablation for olfactory meningioma performed by the Johns Hopkins neurosurgeon Walter Dandy. Both occurrences are said to have influenced Portuguese neurologist Egas Moniz (1874-1955) to commence performing leucotomies on patients beginning in late 1935. Here the authors review the relevant events related to frontal lobe theory leading up to the 1935 Neurological Congress as well as the extent of this meeting's role in the genesis of the modern era of psychosurgery.

https://thejns.org/doi/abs/10.3171/2017.6.FOCUS17249

KEY WORDS leucotomy; psychosurgery; frontal lobe

I N 1936, Egas Moniz published his first report on performing a prefrontal leucotomy on a human patient. ${ }^{34}$ In this report, he introduced the leucotome, a plungerlike device with a narrow shaft designed to extend a wire loop into the brain. After insertion, the leucotome was rotated rapidly, cutting out a piece of brain tissue. Claiming that prefrontal leucotomy was a simple, safe procedure, Moniz accepted the Nobel Prize in Medicine in 1949 for discovering and introducing the therapeutic value of this procedure in patients with psychoses. Ironically, Moniz was later shot by one of his patients who was experiencing psychoses and who had not yet undergone the leucotomy procedure.

Although the unrefined and brutal nature of the leucotomy, as well as the introduction of antipsychotic drugs such as chlorpromazine, led to the procedure falling out of favor in the mid-1950s, surgical solutions for mental illness and frontal lobe theory were highly debated topics in the early part of the 20th century.

Moniz was influenced to begin performing leucotomies in part by a presentation by Yale physiologists Carlyle Jacobsen and John Fulton at the Second International
Neurological Congress in London in 1935. This report described how a chimpanzee with both frontal lobes surgically removed became more cooperative and willing to accomplish tasks. ${ }^{21}$ Regardless of the degree to which this particular study swayed Moniz, the Neurological Congress provided him with a synthesis of the most recent theories of frontal lobe function and neurophysiology. Shortly thereafter, Moniz began performing prefrontal leucotomies, a practice subsequently adapted to lobotomy and popularized by George Washington University neurologist Walter Freeman in the US.

Both the history of psychosurgery ${ }^{5,15,24,32,35,51}$ and Egas Moniz's contributions to leucotomy have been adequately described in the literature. ${ }^{16,23,30,40,43}$ The significant contributions by Jack Pressman and Jack El-Hai use original correspondence to support extensive analysis of the relationship between Moniz and Freeman. ${ }^{14,38}$ Within this history, however, a particular event, the 1935 Neurological Congress, provided a framework of knowledge of both the frontal lobes and psychopathology and offered a stage that yielded the subsequent era of psychosurgery. 


\section{Early Concepts of Mental IIIness and Intervention}

Theories of mental illness in the late 19th century emerged from both neurology and psychiatry, which advocated opposing models of pathophysiology and treatment. It was generally agreed that psychoanalysis was not useful for the most severe of mental illnesses, such as schizophrenia, which were thought to be manifestations of pathological processes. By the early 20th century, "intrapsychic conflict," oxygen insufficiency, sluggish metabolism, leukopenia, and focal infection in the brain had all been put forth as explanations for mental illness. ${ }^{46}$ The proposed treatments were just as varied. These included sleep therapy, electrotherapy, horse blood infusions into the CSF, hysterectomy, induced hypothermia, and "cerebral stimulation" with sodium cyanide and carbon dioxide. As University of Michigan psychologist Elliot Valenstein would later explain, "in this therapeutic and theoretical vacuum, almost any treatment was tried, providing it had the potential for treating large numbers of patients with a minimum of highly trained staff."'46

Surgical solutions for mental illness arose in the late 1880s, when Swiss psychiatrist Gottlieb Burckhardt performed a series of cortical extirpations in 6 patients presenting primarily with original paranoia and chronic mania..$^{32}$ One patient who had received a left temporal topectomy died, and, in part because of criticism garnered from colleagues at the 1889 Berlin Medical Congress, Burckhardt discontinued the practice. In 1910, Estonian neurologist turned neurosurgeon Ludvig Puusepp performed surgeries in which he severed association fibers between the frontal and parietal lobes in manic-depressive patients. ${ }^{38,45}$ Other early surgical approaches intended to alter the frontal lobe included injections of malarial blood via trephined sites as well as reintroduction of the patient's own blood into prefrontal areas. ${ }^{45}$

\section{Origins of Frontal Lobe Theory}

By the time these interventions were being developed, the field of investigation of the frontal lobe was already established. The injury of a Vermont railroad worker, Phineas Gage, in 1848 was one of the earliest cases to expose frontal lobe associations with decision making, judgment, and personality. ${ }^{29}$ Gage suffered an injury in which a tamping iron $3 \mathrm{~cm}$ in diameter passed through his left frontal lobe. A contemporary imaging study by Damasio and colleagues suggests that Gage's injury was more extensive, however, and included the bilateral ventromedial prefrontal cortices. ${ }^{12}$ After initially denying that Gage suffered from any deficits as a result of his injury, his treating physician John Harlow later amended his interpretation of the case in a speech before the Massachusetts Medical Society in 1868 , concluding that Gage had in fact experienced intellectual impairment and personality changes after the incident. ${ }^{29}$ Contemporary analysis corroborates that Gage indeed incurred deficits in rational decision making and emotional processing. ${ }^{12}$

The period between 1870 and 1890 marked the "golden age" of cerebral localization. In 1870, Gustav Fritsch and Eduard Hitzig used electrical stimulation to identify the motor cortex, which suggested the possibility of further functional specialization of the cortices. ${ }^{11,20}$ Numerous subsequent studies emerged elucidating cortical relationships with cognitive behavior and sensory and motor function. ${ }^{4}$ Other studies examining neurological deficits produced by structural alterations such as injury, tumor, or experimentation followed. In the late 1890s, American surgeon Charles Phelps attributed mental changes to the left, but not right, frontal lobe and prefrontal areas after analyzing hundreds of cases of pistol shot wounds. ${ }^{37,47}$ As detailed by Benton, animal studies by Friedrich Goltz and Jacques Loeb in the early 1900s demonstrated that bilateral frontal lobe removal but not ablations of the prefrontal cortex in dogs resulted in "an alteration in character." According to Benton, Shepherd Ivory Franz contributed a series of works from 1902 to 1912 on unilateral and bilateral prefrontal ablations that demonstrated that animal subjects experienced no loss of function after unilateral extirpations, and Leonardo Bianchi subsequently demonstrated that bilateral prefrontal ablations in dogs and primates led to profound changes in personality but failed to evoke sensory or motor deficits. Meanwhile, early surgical procedures on the frontal lobes were documented from 1930 through 1939 in significant studies by Babcock, ${ }^{3}$ Brickner, ${ }^{6-8}$ German and Fox, ${ }^{22}$ Penfield and Evans, ${ }^{36}$ Ackerly, ${ }^{1}$ Karnosh, ${ }^{27}$ and Jefferson (as detailed by Finger). ${ }^{17}$ Because of the intense interest in this subject, the International Neurological Congress, with honored guest Ivan Pavlov, convened in London in 1935 to discuss epilepsy, physiology, and pathology of CSF and the functions of the frontal lobe.

\section{The 1935 International Neurological Congress \\ Planning Group Meeting}

In September 1933, the program committee responsible for planning the 1935 International Neurological Congress convened at the Royal Society of Medicine in London. The last Neurological Congress had taken place in London in 1913, before World War I deferred subsequent meetings. ${ }^{28}$ The planning group chaired by New York neurologist Bernard Sachs selected frontal lobe function as a topic for the 1935 conference..$^{50}$

\section{Second International Neurological Congress}

From July 29 to August 2, 1935, attendees assembled at University College London for the Second International Neurological Congress (Fig. 1). ${ }^{9}$ French neurologist Henri Claude presided over the frontal lobe session. ${ }^{38,50}$ Major presentations included work by French neurosurgeon Clovis Vincent, who delivered a paper titled "Modification of function observed after surgical intervention on the frontal lobes," and neurologist Richard Brickner, of the New York Neurological Institute, who presented a case of bilateral frontal lobectomy for meningioma performed by Johns Hopkins neurosurgeon Walter Dandy. Brickner had assumed care of Dandy's patient 1 year after the surgery and was responsible for neurological and psychological examination of this individual. In addition, Yale neurophysiologist John Fulton and his associate, Carlyle Jacobsen, presented "The functions of the frontal lobes: a compara- 


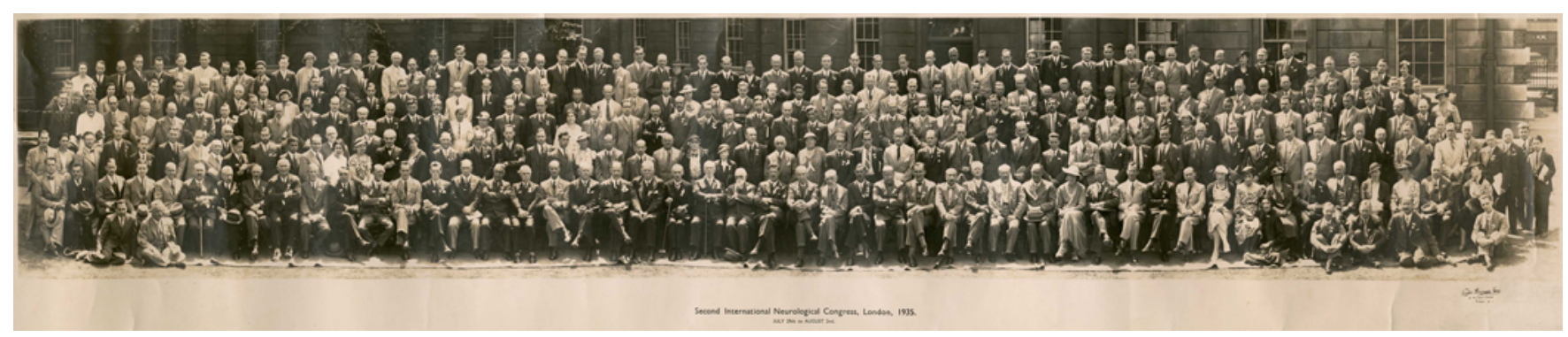

FIG. 1. The attendees at the Second International Neurological Congress, 1935. Individuals of interest (in first seated row) include John Fulton (4th from left), Egas Moniz (19th from left), Bernard Sachs (23rd from left), Ivan Pavlov (24th from left), Otto Marburg (27th from left), and Wilder Penfield (first standing row, 10th from right). London Panoramic Company. Image courtesy of The Queen Square Archives. Photograph is in the public domain.

tive study in monkeys, chimpanzees, and man" at the symposium..$^{10,21}$ Fulton had graduated from Harvard Medical School in 1927 and subsequently completed a neurosurgical internship at Peter Bent Brigham Hospital in Boston under the auspices of Harvey Cushing. After working in the laboratory of Charles Sherrington at the University of Oxford, Fulton joined Yale in 1929, where he became the Sterling Professor of Physiology and founded the nation's first primate research laboratory. ${ }^{13,31}$ At the London Neurological Congress, Fulton and Jacobsen reported on the behavior of 2 chimpanzees, Becky and Lucy, after unilateral frontal lobectomy and subsequent contralateral lobectomy. Becky in particular demonstrated a marked change in personality, absent of temper tantrums and "experimental neuroses" after the second surgery., ${ }^{43}$

\section{Impact on Moniz and the Impetus for Psychosurgery}

Although his expertise lay in cerebral angiographyhe was nominated for the Nobel Prize in 1928 and 1933 for this work-Egas Moniz was captivated by talk of the frontal lobes at the London Neurological Congress. ${ }^{48}$ It has been suggested that Moniz questioned Fulton during the discussion period and asked whether the procedure performed on the primates could be extended to treating psychiatric illness in human patients, perhaps as a less destructive leucotomy. ${ }^{4,25,38}$ Whitaker suggests that while other attendees absorbed the harmful consequences of frontal surgeries, Moniz instead identified an opportunity to exploit such deficits for psychosurgery. ${ }^{48}$

Shortly after the Neurological Congress, Moniz proceeded with his initial attempts at leucotomy in humans. He assigned the psychopathological centers of mental illness and "psychic activity" to the frontal lobes and used this theory to support prefrontal leucotomy, at first implemented by injecting pure ethanol, beginning in late 1935 into 1936, and then by the use of the leucotome..$^{25}$ Moniz's hands were crippled by gout, and he was not a neurosurgeon, so he relied on the assistance of his surgical colleague, Almeida Lima. Moniz rationalized that disrupting the frontal lobe, which "stored [ideas] in the nerve fibers between brain cells," would resolve the problem of "fixed and persistent" patterns of cells responsible for producing psychoses. ${ }^{2,26,33,48}$ In his view, the problem was not one of an anatomical alteration or localized to a particular area. It has been suggested that Moniz, buoyed by the acceptable outcomes garnered in his first few operations, used these results to justify not only the procedure itself, but also this particular theory of psychopathology. ${ }^{25}$

Contemporary analysis has disputed whether the supposed conversation between Moniz and Fulton at the Neurological Congress took place. Historian Jack Pressman has emphasized that Fulton's work provided "confirmation, not inspiration" for Moniz, who "was searching for a neural basis of emotions with a model based largely on the nineteenth century framework of habits," as opposed to the more sophisticated principles used by Fulton and his colleagues. ${ }^{38}$ In other words, Moniz may have been searching for a theory to fit his procedure. Discrepancies among accounts generated from the meeting as well as from Moniz himself further complicate our understanding of the conference's impact. Moniz produced his first report on leucotomy in 1936, in which he published the results of his first 20 patients and described the origins of his work; Moniz did not cite Fulton and Jacobsen, but instead referred extensively to Brickner's study, concluding that "even after extirpation of the two frontal lobes, there remains a psychic life which, although deficient, is nevertheless appreciably better than that of the majority of the insane." 33,49 Multiple authors have further corroborated this notion that Moniz was more interested in Brickner's patient who, after bilateral frontal ablation for olfactory meningioma, developed a flattened affect but remained intellectually intact. ${ }^{19,30,38}$ The historian El-Hai has explained that, although neurosurgeons had always been concerned with patients' functional outcomes, the advent of psychometric testing in the 1920s and 1930s provided a means of assessing psychological sequelae from neurosurgical procedures. The aforementioned patient discussed by Brickner was one of the first cases subject to such analysis, which would support subsequent utility for psychosurgical applications..$^{14}$ For Dandy's part, despite the relevance of his patient to Moniz at the symposium, he seems to have had little to do with lobotomy throughout his career. However, Pressman has cited correspondence between Freeman and Moniz in 1946 in which the former "boasted that even the great neurosurgeon Walter Dandy ... performed one," as if to further justify the procedure on the basis of Dandy's stellar reputation. ${ }^{38}$

Another speaker at the Neurological Congress, renowned neurosurgeon and neuroscientist Wilder Penfield of the Montreal Neurological Institute, presented a patient who underwent frontal lobe removal for a large 
tumor. This case's influence on Moniz has been cited in somewhat cursory fashion, grouping its impact with that of Brickner's patient ${ }^{14}$ however, because of his research group's groundbreaking contributions to the field of cortical localization, Penfield's views on psychosurgery are worthy of consideration. Sedney and Bernstein concluded that "the intentional surgical alteration of personality or the individual psychology of a patient was unacceptable to Penfield, who never pursued this area in spite of his generally aggressive surgical treatments...." ${ }^{\prime 2}$ The authors further cite a conversation in which Penfield accused Freeman of "doing a dangerous thing" with regard to psychosurgery.

Vincent's presentation on prefrontal surgeries, with particular emphasis on the lack of deficits observed after such a procedure, may have also persuaded Moniz to consider leucotomy after the frontal lobe symposium, although Moniz himself denied such influence. ${ }^{4,46}$ Last, in a conclusion that precludes attribution to other parties, it has been suggested that Moniz mulled the possibility of using surgery to treat psychoses more than 2 years before his initial surgeries. ${ }^{5}$ Walter Freeman characterized the impact of the Neurological Congress several years later, explaining that the conference provided a "summing up of knowledge [that] paved the way for ... Moniz to carry into practice his ideas (already developed during the preceding two years)." 19 Freeman was careful to suggest that Moniz was already inclined to perform such surgeries and that the conference further validated his work.

The presentation by Fulton and Jacobsen at the 1935 Neurological Congress was reminiscent of a scene that played out at the Seventh International Medical Congress in London in 1881, a seminal event in medicine attended by the likes of Horsley, Lister, Pasteur, Virchow, and Osler. ${ }^{44}$ During the physiology section meeting, Englishman David Ferrier and German Friedrich Goltz paraded their experimental subjects, a macaque and a dog, respectively, in front of a crowd-as Jacobsen and Fulton had done with their chimpanzees-to demonstrate their opposing views of localization theory. This display, as expected, fostered argument about the significance of the frontal lobes; Ferrier's view, which endorsed specialized functional areas, would emerge triumphant. This particular event has been cited as a watershed moment leading to the modern era of neurosurgery. In a similar parallel, Pressman concluded that "by all accounts, the specific link between neurosurgery and mental disorders was forged at the Second International Neurological Congress" in London. ${ }^{38,41}$

\section{Moniz's Influence on Freeman}

The 1935 Neurological Congress had also facilitated the introduction of Moniz to Walter Freeman, the George Washington University neurologist who would introduce psychosurgery in the US. ${ }^{25}$ Although their initial encounter was limited to a discussion regarding cerebral angiography, an article by Moniz in the journal Lisboa Medicina prompted Freeman to write Moniz in May 1936 expressing interest in his work with leucotomy. ${ }^{38}$ As Pressman explains, Freeman believed that Moniz had finally resolved the pathophysiology of mental illness, not as a localized entity, but as a malfunction in "wiring." Freeman would later describe Moniz's approach to psychosurgery as "the breaking up of constellations of neuron patterns." 19,44 Regarding their approach to the procedure, he wrote that it accomplished "separation of the frontal lobes from the rest of the brain," which "removed the emotional nucleus of psychosis." 19

Freeman and his colleague, neurosurgeon James Watts, performed the first prefrontal lobotomy (leucotomy) in the US on September 14, 1936. ${ }^{46}$ They first followed Moniz's procedure, by which they used an auger to drill 2 holes into the skull over the left and right frontal lobes and then inserted a leucotome into the centrum ovale, but they later altered the procedure to increase the extent of white matter excised. ${ }^{18,19}$ Freeman explained the procedure thus: "the white matter in the lower and upper parts of the frontal lobe is cut by swinging the instrument upward and downward in the plane of the coronal suture." 19 By 1946, Freeman had transitioned to a transorbital approach, at first crudely characterized as an "ice pick lobotomy," given the resemblance of that implement to the instrument involved. ${ }^{38}$ Dogliotti, of Italy, had demonstrated "easy" access to the frontal lobes via this approach through the orbital plate by using a trocar in 1933, although he adopted the method for use with pneumoventriculography. ${ }^{45}$ Freeman's method was so fast and simple that he claimed that a nonsurgeon required only a half day of training to learn the procedure. ${ }^{38}$ This procedure was performed by inserting a metal pick into the corner of each orbital cavity, hammering it through the thin bone in this location with a mallet, and moving it back and forth rapidly, severing the connections to the prefrontal cortex.

In 1947, Freeman and Fulton crossed paths at a meeting on-quite fittingly - the frontal lobes, for the Association for Research in Nervous and Mental Disease, where Fulton harshly criticized Freeman's latest work on transorbital lobotomy. ${ }^{38}$ Fulton had lauded the procedure as a "milestone" in the treatment of mental illness soon after Freeman's initial surgery in $1936^{14}$ and, after a period of working on projects related to World War II, directed his attention to the latest developments on the frontal lobes and psychosurgery in 1946. ${ }^{38}$ According to Pressman's analysis, Fulton's major grievance with "the lobotomists" was that they lacked a sufficient understanding of frontal lobe neurophysiology, which compromised the validity of their surgical procedures. Freeman persisted, however, and by the mid-1950s had performed more than 2000 lobotomies by his own hand.

\section{Conclusions}

Amid much debate and consternation, leucotomy or lobotomy, while imprecise and brutal, had for a time offered a seemingly viable therapy for intractable psychiatric illness when no other treatments were available. The shared history among Moniz, Fulton, and Freeman regarding psychosurgery essentially began at the International Neurological Congress in 1935. Thus, the framing of a body of ideas about frontal lobe theory-cultivated across many institutions and individuals over many years-that occurred at the conference yielded the beginnings of the modern era of psychosurgery practice. 


\section{References}

1. Ackerly S: Instinctive, emotional and mental changes following prefrontal lobe extirpation. Am J Psychiatry 92:717729,1935

2. Archives of Neurology and Psychiatry: Tentatives opératoires dans le traitement de certaines psychoses. Arch Neurol Psychiatry 36:1413-1413, 1936

3. Babcock H: An experiment in the measurement of mental deterioration. Arch Psychol 18:1-105, 1930

4. Benton AL: The prefrontal region: its early history, in Levin HS, Eisenberg HM, Benton AL (eds): Frontal Lobe Function and Dysfunction. New York: Oxford University Press, 1991

5. Berrios GE: The origins of psychosurgery: Shaw, Burckhardt and Moniz. Hist Psychiatry 8:61-81, 1997

6. Brickner RM: Bilateral frontal lobectomy: follow-up report of a case. Arch Neurol Psychiatry 41:580-585, 1939

7. Brickner RM: The Intellectual Functions of the Frontal Lobes: A Study Based Upon Observation of a Man After Partial Bilateral Lobectomy. New York: Macmillan, 1936

8. Brickner RM: An interpretation of frontal lobe function based upon the study of a case of partial bilateral frontal lobectomy. Proc Assoc Res Nerv Ment Dis 13:259, 336, 1932

9. British Medical Journal: International Neurological Congress in London. BMJ 2:223-225, 1935

10. British Medical Journal: International Neurological Congress in London: later proceedings. BMJ 2:269-272, 1935

11. Carlson C, Devinsky O: The excitable cerebral cortex. Fritsch G, Hitzig E. Über die elektrische Erregbarkeit des Grosshirns. Arch Anat Physiol Wissen 1870; 37:300-32. Epilepsy Behav 15:131-132, 2009

12. Damasio H, Grabowski T, Frank R, Galaburda AM, Damasio AR: The return of Phineas Gage: clues about the brain from the skull of a famous patient. Science 264:1102-1105, 1994

13. Davey LM: John Farquhar Fulton. Neurosurgery 43:185187, 1998

14. El-Hai J: The Lobotomist: A Maverick Medical Genius and His Tragic Quest to Rid the World of Mental Illness. Hoboken, NJ: Wiley, 2007

15. Feldman RP, Goodrich JT: Psychosurgery: a historical overview. Neurosurgery 48:647-659, 2001

16. Ferro JM: Egas Moniz (1874-1955). J Neurol 250:376-377, 2003

17. Finger S: Origins of Neuroscience: A History of Explorations into Brain Function. Oxford: Oxford University Press, 2005

18. Freeman W, Watts JW: An interpretation of the functions of the frontal lobe: based upon observations in forty-eight cases of prefrontal lobotomy. Yale J Biol Med 11:527-539, 1939

19. Freeman W, Watts JW, Hunt T: Psychosurgery; Intelligence, Emotion and Social Behavior Following Prefrontal Lobotomy for Mental Disorders. Springfield, IL: Charles C Thomas, 1942

20. Fritsch G, Hitzig E: Electric excitability of the cerebrum (Über die elektrische Erregbarkeit des Grosshirns) [Crump T, Lama S, transl.]. Epilepsy Behav 15:123-130, 2009

21. Fulton JF, Jacobsen CF: The functions of the frontal lobes: A comparative study in monkeys, chimpanzees, and man, in Abstracts of the Second International Neurological Congress. London: International Neurological Congress, 1935, pp 70-71

22. German WJ, Fox JC: Observations following unilateral lobectomies. Proc Assoc Res Nerv Ment Dis 13:378-434, 1934

23. Gross D, Schäfer G: Egas Moniz (1874-1955) and the "invention" of modern psychosurgery: a historical and ethical reanalysis under special consideration of Portuguese original sources. Neurosurg Focus 30(2):E8, 2011

24. Heller AC, Amar AP, Liu CY, Apuzzo MLJ: Surgery of the mind and mood: a mosaic of issues in time and evolution. Neurosurgery 59:720-739, 2006
25. Johnson JM: American Lobotomy: A Rhetorical History. Ann Arbor: University of Michigan Press, 2014

26. Journal of the American Medical Association: Tentatives opératoires dans le traitement de certaines psychoses. JAMA 108:1828-1828, 1937

27. Karnosh LJ: The clinical aspects of frontal lobe disease. J Indiana State Med Assoc 28:568-572, 1935

28. Kinnier Wilson SA (ed): Editorial. International Neurological Congress, Berne. J Neurol Psychopathol 12:66-68, 1931

29. Kolb B, Whishaw IQ: Brain and Behaviour: Revisiting the Classic Studies. Los Angeles: SAGE, 2016

30. Kotowicz Z: Gottlieb Burckhardt and Egas Moniz-two beginnings of psychosurgery. Gesnerus 62:77-101, 2005

31. Leake CD: Eloge: John Farquhar Fulton, 1899-1960. Isis 51:560-562, 1960

32. Manjila S, Rengachary S, Xavier AR, Parker B, Guthikonda M: Modern psychosurgery before Egas Moniz: a tribute to Gottlieb Burckhardt. Neurosurg Focus 25(1):E9, 2008

33. Moniz, E. Tenatives opératoires dans le traitement de certaines psychoses. Paris: Masson \& Cie, 1936

34. Moniz E: Essai d'un traitement chirurgical de certaines psychoses. Bull Acad Méd 115:385-392, 1936

35. Patel SR, Aronson JP, Sheth SA, Eskandar EN: Lesion procedures in psychiatric neurosurgery. World Neurosurg 80:S31.e9-S31.e16, 2013

36. Penfield W, Evans J: Functional defects produced by cerebral lobectomies. Res Publ Assoc Res Nerv Ment Dis 13:352377, 1934

37. Phelps C: Traumatic Injuries of the Brain and its Membranes. New York: Appleton, 1898

38. Pressman JD: Last Resort: Psychosurgery and the Limits of Medicine. Cambridge, UK: Cambridge University Press, 1998

39. Raudam E, Kaasik AE: Ludwig Puusepp 1875-1942. Surg Neurol 16:85-87, 1981

40. Sassard R, O'Leary JP: Egas Moniz: pioneer of cerebral angiography. Am Surg 64:1116-1117, 1998

41. Schiller F: The mystique of the frontal lobes. Gesnerus 42: 415-424, 1985

42. Sedney CL, Bernstein M: Wilder Penfield - bioethicist. Can J Neurol Sci 41:177-181, 2014

43. Tierney AJ: Egas Moniz and the origins of psychosurgery: a review commemorating the 50th anniversary of Moniz's Nobel Prize. J Hist Neurosci 9:22-36, 2000

44. Tyler KL, Malessa R: The Goltz-Ferrier debates and the triumph of cerebral localizationalist theory. Neurology 55:1015-1024, 2000

45. Uylings HBM, Van Eden CG, De Bruin JPC, Corner MA, Feenstra MGP (eds): The Prefrontal Cortex: Its Structure, Function and Pathology. Amsterdam: Elsevier, 1990

46. Valenstein ES: Great and Desperate Cures: The Rise and Decline of Psychosurgery and Other Radical Treatments for Mental Illness. New York: Basic Books, 1986

47. Verplaetse J: Localising the Moral Sense: Neuroscience and the Search for the Cerebral Seat of Morality, 18001930. Dordrecht: Springer, 2009

48. Whitaker R: Mad in America: Bad Science, Bad Medicine, and the Enduring Mistreatment of the Mentally Ill. New York: Basic Books, 2010

49. Wilkins RH: Neurosurgical classic-XXVI. J Neurosurg 21:1108-1114, 1964

50. Wilson K: Occasional notes. Second International Neurological Congress, London, 1935. J Neurol Psychopathol 15:283-288, 1935

51. Wind JJ, Anderson DE: From prefrontal leukotomy to deep brain stimulation: the historical transformation of psychosurgery and the emergence of neuroethics. Neurosurg Focus 25(1):E10, 2008 


\section{Disclosures}

The authors report no conflict of interest concerning the materials or methods used in this study or the findings specified in this paper.

\section{Author Contributions}

Conception and design: Menacho. Acquisition of data: Boettcher.
Drafting the article: both authors. Critically revising the article: both authors. Reviewed submitted version of manuscript: both authors. Approved the final version of the manuscript on behalf of both authors: Menacho.

\section{Correspondence}

Sarah T. Menacho, Department of Neurosurgery, Clinical Neurosciences Center, Fifth Fl., University of Utah, 175 North Medical Dr., Salt Lake City, UT 84132. email: sarah.menacho@hsc. utah.edu. 